\title{
Interleukin 1 Stimulates Fibroblasts to Produce Granulocyte-Macrophage Colony-stimulating Activity and Prostaglandin $\mathrm{E}_{\mathbf{2}}$
}

\author{
James R. Zucali, Charles A. Dinarello, David J. Oblon, Mary Ann Gross, Lisa Anderson, and Roy S. Weiner \\ Division of Medical Oncology, Department of Medicine, and Bone Marrow Transplantation Program, University of Florida, \\ Gainesville, Florida 32610; and Division of Experimental Medicine, Department of Medicine,
}

Tufts University School of Medicine, Boston, Massachusetts 03222

\begin{abstract}
Granulocyte-macrophage colony-stimulating activity (GM-CSA) can be produced by a variety of normal cell types including mononuclear phagocytes, activated $T$ lymphocytes, endothelial cells, and fibroblasts. Recent evidence shows that a major role of the monocyte-macrophage is the recruitment of environmental cells, i.e., fibroblasts, to produce GM-CSA. In this study we have identified interleukin 1 (IL-1) as a monokine that stimulates fibroblasts to produce and release GM-CSA and prostaglandin $E_{2}\left(P E_{2}\right)$. Both purified human monocyte-derived IL-1 and human recombinant IL-1 $\left(10^{-10} \mathrm{M}\right)$ can be substituted for monocyteconditioned medium in stimulating fibroblast GM-CSA and PGE $_{2}$ production. Both forms of IL-1 stimulate fibroblasts to produce GM-CSA and PGE $_{2}$ in a dose-dependent fashion. The fibroblhst-stimulating activity found in monocyte-conditioned medium was completely blocked by anti-IL-1. We conclude that monocytes produce IL-1, and that monocyte-derived $I-1$ induces fibroblasts to produce GM-CSA and PGE 2 .
\end{abstract}

\section{Introduction}

Granulocyte-macrophage colony-stimulating activity (GMCSA) ${ }^{1}$ represents a family of glycoproteins that promote differentiation of hematopoietic progenitor cells to mature granulocytes and macrophages. Clonal proliferation of human neutrophil and macrophage progenitors in vitro depends upon the continuous presence of GM-CSA. A variety of cell types, including mononuclear phagocytes $(1,2)$, T lymphocytes $(3,4)$, vascular endothelial cells $(5,6)$, and fibroblasts $(7)$, can produce GM-CSA. Other reported sources of GM-CSA are either not adequately characterized as to cell type, or are established tumor cell lines in which physiologic relevance is questionable. Although many normal cell types are reported to produce GMCSA, they do require stimulation with exogenous modulators such as endotoxin $(8-10)$ or mitogens $(11,12)$. Several groups have suggested that monocytes and $\mathrm{T}$ lymphocytes interact to

Address reprint requests to Dr. Zucali, Division of Medical Oncology, Department of Medicine, University of Florida, Gainesville, FL 32610. Received for publication 10 December 1985.

1. Abbreviations used in this paper: anti-IL-1, antibody to interleukin1; GM-CSA, granulocyte-macrophage colony-stimulating activity; hrIL1, human recombinant interleukin 1; IL-1, interleukin 1; LPS, lipopolysaccharide; MRA, monocyte-derived recruiting activity; $\mathrm{PGE}_{2}$, prostaglandin $\mathrm{E}_{2}$; pI, isoelectric point.

J. Clin. Invest.

(c) The American Society for Clinical Investigation, Inc.

0021-9738/86/06/1857/07 \$1.00

Volume 77, June 1986, 1857-1863 modulate the production of GM-CSA (13-15). These investigators have demonstrated that incubation of monocytes with $\mathrm{T}$ lymphocytes in the presence of antigen or mitogen produces significantly more GM-CSA than either cell type incubated alone.

Recently, Bagby et al. (16-18) have proposed that the major role of the monocyte-macrophage in granulopoiesis is not by the production of GM-CSA, but by the recruitment of other cells, i.e., T lymphocytes, endothelial cells, and neonatal skin fibroblasts, to produce GM-CSA. These authors have described a nondialyzable factor or factors present in monocyte-conditioned medium that stimulates the production of GM-CSA by these accessory cells. They have termed this monokine as monocyte-derived recruiting activity (MRA), and have also shown that endotoxin augments monocyte production of MRA (19). Thus, MRA may be a key biologic regulator of GM-CSA production and consequently of granulopoiesis.

Monocyte products have also been associated with chronic tissue inflammation and elevated prostaglandin $\mathrm{E}_{2}\left(\mathrm{PGE}_{2}\right)$ levels at the site of injury (20). Monocytes or macrophages actively modulate fibroblast proliferation and prostaglandin production. Monocyte-conditioned medium contains a factor that results in a 50-200-fold stimulation of $\mathrm{PGE}_{2}$ biosynthesis from dermal fibroblasts (21), synovial cells (22), and lung fibroblasts (23). This monocyte-derived factor has recently been identified as interleukin 1 (IL-1) $(24,25)$.

In this study, we have identified the monokine that stimulates fibroblasts to produce and release GM-CSA and PGE 2 as IL-1. Both purified monocyte-derived IL-1 and human recombinant (hr) IL-1 reproduce the biologic activity found in monocyteconditioned medium. In addition, a polyclonal antibody to IL1 completely abolishes the biologic activity of MRA found in monocyte-conditioned medium.

\section{Methods}

Isolation of peripheral blood monocytes. Peripheral blood and bone marrow were obtained from normal donors who had given informed consent. Peripheral blood leukocytes were isolated after semicontinuous flow pheresis (26). The buffy coat was diluted with two volumes of Hanks' balanced salt solution without calcium and magnesium and was centrifuged at $150 \mathrm{~g}$ for $10 \mathrm{~min}$ to remove platelets. This cell suspension was centrifuged over Ficoll-Hypaque (specific gravity 1.078) to remove contaminating granulocytes and erythrocytes. The mononuclear cells at the interface were collected and separated into two populations, monocytes and lymphocytes, by elutriation centrifugation as previously reported $(27,28)$. Briefly, counterflow centrifugation elutriation was performed using a Sanderson-designed separation chamber fitted to a Beckman model J-21C centrifuge (Beckman Instruments, Inc., Fullerton, CA). Up to $1.5 \times 10^{9}$ mononuclear cells were loaded into the chamber and elutriation was performed at $10^{\circ} \mathrm{C}$ with flow rates of 18 and $28 \mathrm{ml} / \mathrm{min}$ against a force of $867 \mathrm{~g}(3,000 \mathrm{rpm})$. Each cell fraction was collected by centrifugation ( $300 \mathrm{~g}$ for $10 \mathrm{~min}$ ), and the cell volume profile was determined with a Particle Data, Inc. (Elmhurst, IL) System 80 pulse height 
analyzer. Using this technique, monocytes ( $380 \mu \mathrm{m}^{3}$ modal volume) were collected as a homogeneous population. Both the separated monocytes as well as unseparated peripheral blood mononuclear cells were further subjected to 2-aminoethylisothiouronium bromide hydrobromide-treated sheep erythrocyte rosette depletion to remove $T$ lymphocytes before use. Non-rosetting cells were separated by centrifugation through Ficoll-Hypaque. The purity of nonrosetting cells was determined by using OKT3 (Ortho Pharmaceutical, Raritan, NJ) monoclonal antibody and indirect immunofluorescence with fluorescein-conjugated goat antimouse IgG (Cappel Laboratories, Cochranville, PA). The cells were analyzed with both fluorescence microscopy and a Coulter Electronics Inc. (Hialeah, FL) model C flow cytometer. Background staining was determined on cells treated with nonimmune mouse immunoglobulins and second antibody. In addition, the monocyte monoclonal antibody LeuM3 (Becton, Dickinson \& Co., Sunnyvale, CA) was used for analysis of monocyte specificity and compared with cytochemical staining for monocytes.

Monocytes were identified on cytocentrifuge prepared slides stained with Wright's Giemsa and nonspecific esterase using alpha naphthal acetate as substrate (29). The monocyte populations used in all experiments described contained $<2 \%$ OKT3-positive and $>98 \%$ LeuM3-positive and $>98 \%$ nonspecific esterase-positive cells.

Monocyte-conditioned medium studies. Various cell concentrations of separated fresh and cryopreserved monocyte populations were cultured for $2 \mathrm{~d}$ in alpha-minimum essential medium containing $6 \%$ fetal bovine serum with and without $10^{-6} \mathrm{M}$ indomethacin. This concentration of indomethacin prevents prostaglandin production by normal monocytes and macrophages (30). In some cultures, endotoxin (LPS) (lipopolysaccharide B, Salmonella typhosa, Difco Laboratories, Detroit, MI) was added at the time of initiation of monocyte cultures. To produce monocyte-conditioned medium, monocytes were allowed to remain adhered to the dish and culture medium was added. The conditioned media were harvested, dialyzed, and added directly to agar cultures for the measurement of GM-CSA content or added to fibroblast cultures for $24 \mathrm{~h}$ or as described in the time course studies. The resulting fibroblast supernatants were collected and assayed for GM-CSA in agar cultures.

Purification of human monocyte-derived IL-1. Human platelet pheresis by-products were used as a source of mononuclear cells; the mononuclear cells were adjusted to a concentration of $1 \times 10^{7} / \mathrm{ml}$ in RPMI 1640 (Microbiological Associates, Bethesda, MD) in 1\% human AB serum. Cells were incubated at $37^{\circ} \mathrm{C}$ for $1.5 \mathrm{~h}$ and the nonadherent cells were removed by vigorous shaking. The adherent cell population was stimulated with opsonized heat-killed Staphylococcus albus and incubated for $36 \mathrm{~h}$. The supernate was removed, centrifuged at $3,000 \mathrm{~g}$, and filtered. The supernate was purified by sequential immunoabsorption, gel filtration, and chromatofocusing. Details of the purification procedures and the antibody used to make the immunoabsorbent have been published previously $(31,32)$. IL-1 with isoelectric point (pI) 6.8-7.2 eluted from the chromatofocusing step as a homogeneous $17.5-\mathrm{kD}$ molecule determined by sodium dodecyl sulfate-polyacrylamide gel electrophoresis (SDS-PAGE).

Recombinant human (hr) IL-1. The IL-1 complementary DNA (cDNA) expression vector was constructed by isolating the 1,112-base pair (bp) NcoI-X mnI fragment (bp 295-1407) from the IL-1 cDNA plasmid pcD 12-1-8 (33) and inserting it into Escherichia coli expression plasmid. The hrIL-1 contains amino acids 71-269 of the IL-1 precursor. The molecular weight of the hrIL-1 is $24.5 \mathrm{kD}$. hrIL-1-producing bacteria were grown at $37^{\circ} \mathrm{C}$ and lysed, and the hrIL-1 was extracted from the insoluble cellular fraction with $8 \mathrm{M}$ urea. hrIL-1 was purified by sequential ion-exchange and either gel-filtration chromatography or fast protein liquid chromatography. The hrIL-1 was stored at $-70^{\circ} \mathrm{C}$ in a $0.15 \mathrm{M}$ phosphate-buffered saline (PBS), pH 6.8. The identity of the purified hrIL-1 was confirmed by amino acid composition and the sequence of the amino acid terminal heptapeptide. Protein concentration was determined by the Bradford method using a bovine serum albumin (BSA) standard. Purity was assessed by SDS-PAGE with Coomassie blue or silver staining. The hrIL-1 is estimated to be greater than $99 \%$ pure. The endotoxin concentration of the homogeneous hrlL-1 was $\sim 20 \mathrm{pg} / \mu \mathrm{g}$ of IL-1 protein.
Endotoxin assay. All culture materials used were tested for the presence of endotoxin using the Limulus lysate assay (Sigma Chemical Co., St. Louis, MO) (34). The lysate used in these studies can detect levels of endotoxin as low as $50 \mathrm{pg} / \mathrm{ml}$. Only culture medium containing $<50$ $\mathrm{pg} / \mathrm{ml}$ endotoxin were used except where endotoxin was intentionally added.

Fibroblast cultures. Human lung fibroblasts (CL 202) were obtained from the American Type Tissue Culture Collection and cultured in Dulbecco's modified Eagle's medium supplemented with $10 \%$ fetal bovine serum. In the experiments described, fibroblasts from the first to the tenth passage were used; and the cell density ranged from 1 to $5 \times 10^{4}$ cells per square centimeter. Cells were subcultured by brief $\left(1 \mathrm{~min}, 37^{\circ} \mathrm{C}\right)$ treatment with $0.05 \%$ trypsin/0.02\% disodium EDTA (wt/vol in PBS) and resuspended in fresh Dulbecco's modified Eagle's medium $+10 \%$ fetal bovine serum and reseeded at a 1:5 dilution in 35-mm culture plates. At least $24 \mathrm{~h}$ were allowed to elapse after initial seeding or subculture to obtain confluence before an experiment was begun. The fibroblast cell culture medium was replaced with $10-50 \%$ monocyte-conditioned medium, with or without a 1:100 dilution of the IgG fraction of rabbit anti-human IL-1, various concentrations of human IL-1 (purified or recombinant IL-1), or control medium diluted with fibroblast culture medium, and the cultures were returned to the incubator for an additional $24 \mathrm{~h}$. Controls contained diluted medium but no fibroblast cells. After $24 \mathrm{~h}$, the medium was aspirated and centrifuged $(200 \mathrm{~g}, 5 \mathrm{~min})$, and the supernatants were either assayed for GM-CSA or $\mathrm{PGE}_{2}$ the same day or stored at $-20^{\circ} \mathrm{C}$ until tested.

GM-CSA assay. Low-density bone marrow cells from normal volunteers were prepared by centrifugation over Ficoll-Hypaque. Cell suspensions were depleted of monocytes and $\mathrm{T}$ lymphocytes by two sequential adherences to culture plates for $1 \mathrm{~h}$ each after which the nonadherent cells were subjected to incubation with washed 2-aminoethylisothiouronium bromide hydrobromide-treated sheep erythrocytes followed by centrifugation through Ficoll-Hypaque. The nonadherent, nonrosetting, low-density bone marrow cells contained $<2 \%$ monocytes and $<2 \% \mathrm{~T}$ lymphocytes when analyzed for immunofluorescence against LeuM3 and OKT3 monoclonal antibodies, respectively. For each sample, $5 \times 10^{4} \mathrm{~T}$ lymphocyte-depleted, nonadherent, light density bone marrow cells were cultured in $1 \mathrm{ml}$ of $0.3 \%$ agar containing alpha-minimum essential medium supplemented with $10 \%$ fetal bovine serum. Sources of GM-CSA were $10 \%$ conditioned medium from the various monocyte or fibroblast cultures, or supernatant of the human bladder carcinoma cell line 5637 at 5\%, which served as a positive GM-CSA control. The negative control contained $10 \% \mathrm{vol} / \mathrm{vol}$ alpha-medium alone. Colonies ( $>40$ cells) and clusters ( $3-40$ cells) were counted after $10-11 \mathrm{~d}$ of culture in a humidified atmosphere of $7.5 \% \mathrm{CO}_{2}$ in air at $37^{\circ} \mathrm{C}$. Differences between colony counts were considered significant if the $P$ value was $<0.05$ with Student's $t$ test.

Cytochemical staining of CFU-GM colonies. After enumerating the number of CFU-GM, each culture was double stained for specific and nonspecific esterases according to the method described by Kubota et al. (35). For alpha-napthol butyrate esterase (a nonspecific esterase characteristic of the monocyte-macrophage lineage), the cultures were covered with a substrate solution containing one capsule Fast Blue RR salt (Sigma Chemical Co.) for $15 \mathrm{~min}$ at room temperature and then washed with distilled water and air dried. This was followed by staining with napthol 3-hydroxy-2-naphthoic acid 2-methoxyanilide chloroacetate (a specific esterase characteristic of neutrophilic granulocytes). The cultures were covered with a substrate solution containing one capsule of Fast Corinth V salt (Sigma Chemical Co.) for $\mathbf{3 0} \mathrm{min}$ at room temperature and then washed with distilled water and air-dried. Using this double-staining procedure, mature and immature neutrophilic granulocytes demonstrated a strong positive cytoplasmic red staining whereas monocytes or macrophages demonstrated a brown-black dye precipitate within the cells.

$P G E_{2}$ assay. $\mathrm{PGE}_{2}$ was measured with a radioimmunoassay that measured $\mathrm{PGE}_{2}$ levels by competitive inhibition of unlabeled $\mathrm{PGE}_{2}$ with tritium-labeled $\mathrm{PGE}_{2}$ for rabbit anti-PGE ${ }_{2}$ antibody (Sigma Chemical). Briefly, [ $\left.{ }^{3} \mathrm{H}\right] \mathrm{PGE}_{2}$ (Amersham Corp., Arlington Heights, IL) was diluted in Sorenson's buffer to obtain 2,000-3,000 cpm/0.1 ml. PGE 2 standards were prepared in Sorenson's buffer in the range from 10 to $0.020 \mathrm{ng} /$ 
ml. Anti-PGE 2 was reconstituted and titrated to give a working dilution such that $45-55 \%$ of the total counts would bind. All samples (conditioned medium from monocytes or resulting fibroblast cultures) including standards and controls were run in duplicate. A charcoal-dextran buffer was used to bind the free $\left[{ }^{3} \mathrm{H}\right] \mathrm{PGE}_{2}$ to the charcoal, which was pelleted leaving the $\left[{ }^{3} \mathrm{H}\right] \mathrm{PGE}_{2}$ that was bound to the antibody to be counted in the supernatant. A standard curve was constructed for each assay after calculating the percent specific binding of the standards and unknowns by plotting logit \% $\mathrm{B}$ (where \% $\mathrm{B}$ is the percent specific binding) versus log $\mathrm{PGE}_{2}$ concentration for each standard, and the unknown concentrations were read from this curve.

\section{Results}

In four experiments, summarized in Table I, monocytes cultured in the absence of endotoxin (LPS) do not produce biologically active GM-CSA as measured by the ability of their conditioned medium to stimulate nonadherent, $T$ lymphocyte-depleted human bone marrow cells to produce granulocyte and macrophage colonies. This observation is consistent with previous published data $(10,19)$. In contrast, stimulation of $10^{5}$ monocytes $/ \mathrm{ml}$ by as little as $10 \mathrm{ng} / \mathrm{ml}$ of LPS results in biologically detectable GM-CSA (Table II). In addition, no detectable $\mathrm{PGE}_{2}$ is seen in the conditioned medium of monocytes cultured in the absence of LPS; whereas detectable $\mathrm{PGE}_{2}$ is seen when $10^{5}$ monocytes/ $\mathrm{ml}$ have been stimulated with $10 \mathrm{ng} / \mathrm{ml}$ of LPS. Table II shows that monocytes are not dependent on the addition of LPS to release a factor (monokine), which causes fibroblasts to produce and release GM-CSA. LPS addition, however, does augment the production of this monokine such that conditioned medium from as few as $5 \times 10^{3}$ monocytes $/ \mathrm{ml}$ will stimulate maximal colony and cluster formation in the granulocyte-macrophage colony assay. The amount of PGE released by the cultured fibroblasts is also greater in the presence of added LPS. Although not shown, endotoxin ( $10 \mathrm{ng}$ to $1 \mu \mathrm{g} / \mathrm{ml}$ ) diluted in complete medium did not stimulate fibroblast monolayers to produce GM-

Table I. Effect of Monocyte-conditioned Medium on GM-CSA and PGE 2 Production

\begin{tabular}{llc}
\hline Absence of endotoxin & GM-CSA & PGE $_{2}$ \\
\hline monocytes $/ m l$ & colonies + clusters & $p g / m l$ \\
$1 \times 10^{4}$ & 0 & $<20$ \\
$5 \times 10^{4}$ & 0 & $<20$ \\
$1 \times 10^{5}$ & 0 & $<20$ \\
$1 \times 10^{6}$ & 0 & $<20$ \\
\hline Presence of endotoxin & GM-CSA & $\mathrm{PGE}_{2}$ \\
\hline monocytes $/$ ml & colonies + clusters & $\mathrm{pg} / \mathrm{ml}$ \\
$1 \times 10^{4}$ & 0 & $<20$ \\
$5 \times 10^{4}$ & 0 & $\mathrm{ND}$ \\
$1 \times 10^{5}$ & $62 \pm 8^{*}$ & $70 \pm 12$ \\
$5 \times 10^{5}$ & $189 \pm 19$ & $\mathrm{ND}$ \\
$1 \times 10^{6}$ & $\mathrm{ND}$ & $269 \pm 24$ \\
& &
\end{tabular}

Monocyte supernatants were collected from monocytes cultured in the presence and absence of $10 \mathrm{ng} / \mathrm{ml}$ endotoxin on the second day of culture, diluted 1:2 with complete medium, and assayed for GM-CSA and $\mathrm{PGE}_{2}$. ND, not done.

* Results are expressed as means \pm 1 SEM.
Table II. Effect of Monocyte-conditioned Medium on Fibroblast Production of GM-CSA and PGE $E_{2}$ Production

\begin{tabular}{lll}
\hline Absence of endotoxin & GM-CSA & PGE $_{2}$ \\
\hline monocytes $/ m l$ & colonies + clusters & $p g / m l$ \\
0 & 0 & $<20$ \\
$5 \times 10^{3}$ & $21 \pm 7^{*}$ & $\mathrm{ND}$ \\
$1 \times 10$ & $39 \pm 13$ & $110 \pm 42$ \\
$5 \times 10^{4}$ & $173 \pm 21$ & $850 \pm 70$ \\
$1 \times 10^{5}$ & $184 \pm 18$ & $1,150 \pm 350$ \\
$1 \times 10^{6}$ & $204 \pm 16$ & $1,400 \pm 170$ \\
\hline Presence of endotoxin & $\mathrm{GM}-\mathrm{CSA}$ & $\mathrm{PGE}$ \\
\hline monocytes $/$ ml & colonies + clusters & $p g / m l$ \\
0 & 0 & $<20$ \\
$5 \times 10^{3}$ & $205 \pm 11$ & $\mathrm{ND}$ \\
$1 \times 10^{4}$ & $202 \pm 21$ & $200 \pm 42$ \\
$5 \times 10^{4}$ & $226 \pm 22$ & $\mathrm{ND}$ \\
$1 \times 10^{5}$ & $212 \pm 17$ & $3,420 \pm 160$ \\
$5 \times 10^{5}$ & $208 \pm 21$ & $\mathrm{ND}$ \\
$1 \times 10^{6}$ & $\mathrm{ND}$ & $5,700 \pm 1,420$
\end{tabular}

Monocyte-conditioned medium was collected from monocytes cultured in the presence or absence of $10 \mathrm{ng} / \mathrm{ml}$ endotoxin on the second day of culture, diluted 1:2 with complete medium, and placed on fibroblast monolayers for $24 \mathrm{~h}$ after which the fibroblast supernatant was harvested and assayed for GM-CSA and $\mathrm{PGE}_{2}$. ND, not done. * Results are expressed as means \pm 1 SEM.

CSA. Addition of $10^{-6} \mathrm{M}$ indomethacin at the time of monokine production or at the time of monokine stimulation of GM-CSA production by fibroblasts had no effect on the amount of GMCSA detected but completely inhibited $\mathrm{PGE}_{2}$ production by fibroblasts. The resultant fibroblast-conditioned medium stimulated by monokine obtained from $10^{5}$ monocytes $/ \mathrm{ml}$ and cultured in the absence of indomethacin contained $221 \pm 19$ colonies and $3,840 \mathrm{pg} / \mathrm{ml} \mathrm{PGE}$; whereas fibroblast-conditioned medium obtained from similar cultures in the presence of $10^{-6}$ indomethacin contained $217 \pm 11$ colonies and $<20 \mathrm{pg} / \mathrm{ml}$ of $\mathrm{PGE}_{2}$. No differences in results were seen whether monocytes were used immediately after separation or whether monocytes were used after cryopreservation for various lengths of time.

Next we determined the time course of GM-CSA production by fibroblast cultures stimulated with monocyte-conditioned medium. Fig. 1 shows that detectable GM-CSA by fibroblasts did not appear until $4 \mathrm{~h}$ of culture in the presence of $50 \%$ monocyte-conditioned medium with maximal levels detected by $8 \mathrm{~h}$ of culture. This level was maintained through $48 \mathrm{~h}$ of culture. Similar results were seen when IL-1 was substituted for monocyte-conditioned medium. Based upon these results, we cultured fibroblasts in the presence of monocyte-conditioned medium or IL-1 for $24 \mathrm{~h}$ in all subsequent studies.

Purified human monocyte IL-1 has the same effect upon fibroblast monolayers as crude monocyte-conditioned medium (Fig. 2). A dose response for both GM-CSA and $\mathrm{PGE}_{2}$ production by fibroblasts occurs when between 1 and $4 \mathrm{U} / \mathrm{ml}$ of purified IL-1 are cultured for $24 \mathrm{~h}$ with human fibroblasts. Similarly, recombinant IL-1 when added to fibroblast cultures for $24 \mathrm{~h}$, also showed a dose-response effect on the ability of fibroblasts to produce and release GM-CSA and PGE $_{2}$ (Fig. 3). Purified or 


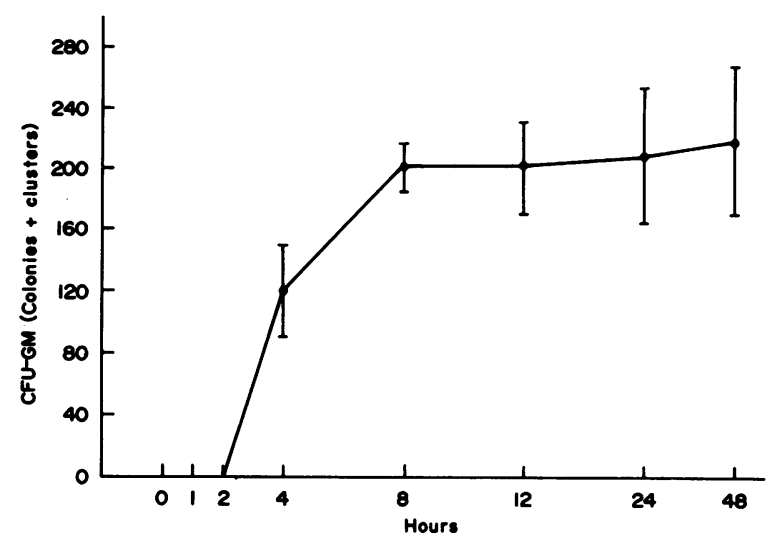

Figure 1. Time course of GM-CSA production by fibroblast monolayers stimulated with monocyte-conditioned medium. Fibroblast monolayers were incubated with $50 \%$ monocyte conditioned medium for up to $48 \mathrm{~h}$ of culture. The resultant fibroblast-conditioned medium was assayed at $10 \%$ in the CFU-GM colony assay. Each point represents the mean CFU-GM (colonies + clusters) of five to six observations. Vertical lines indicate \pm 1 SEM.

recombinant IL-1 alone had no effect on the colony assay for CFU-GM or the radioimmunoassay for $\mathrm{PGE}_{2}$.

As further proof that the activity found in monocyte-conditioned medium was IL-1, studies were conducted with an antibody to IL-1 (anti-IL-1). Table III shows that a 1:100 dilution of this antibody completely blocked the stimulation of fibroblast GM-CSA production seen by $50 \%$ monocyte-conditioned medium collected in the absence of LPS. A 1:100 dilution of antiIL-1 significantly reduced but did not completely block stimulation of fibroblasts to produce GM-CSA by $50 \%$ monocyteconditioned medium collected in the presence of $100 \mathrm{ng}$ of LPS.

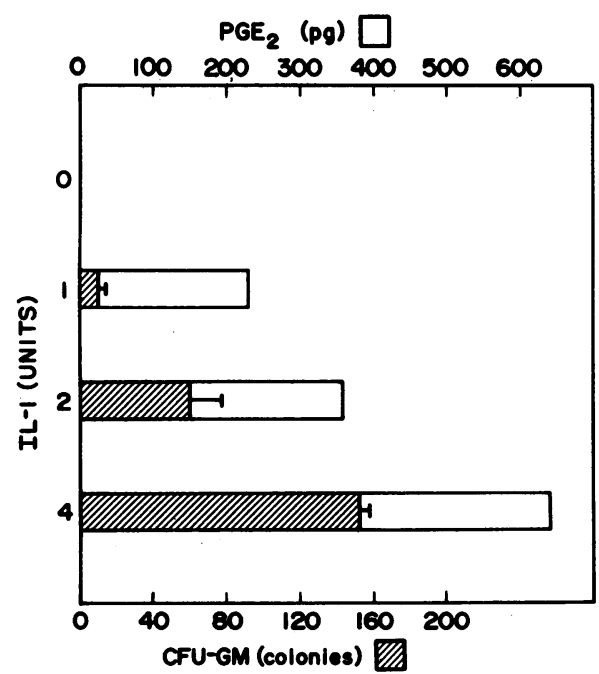

Figure 2. Influence of purified human IL-1 on GM-CSA and PGE production by fibroblast monolayers. Increasing concentrations (1-4 $\mathrm{U})$ of purified IL-1 were added to confluent fibroblast cultures for 24 $h$. The resultant fibroblast-conditioned medium was assayed at $10 \%$ in the CFU-GM colony assay and for $\mathrm{PGE}_{2}$ using the radioimmunoassay. Each hatched bar represents the mean CFU-GM (colonies) \pm 1 SEM of six observations. Each open bar represents the mean $\mathrm{PGE}_{2}$ value from duplicate observations taken from the dose-response curve for $\mathrm{PGE}_{2}$.

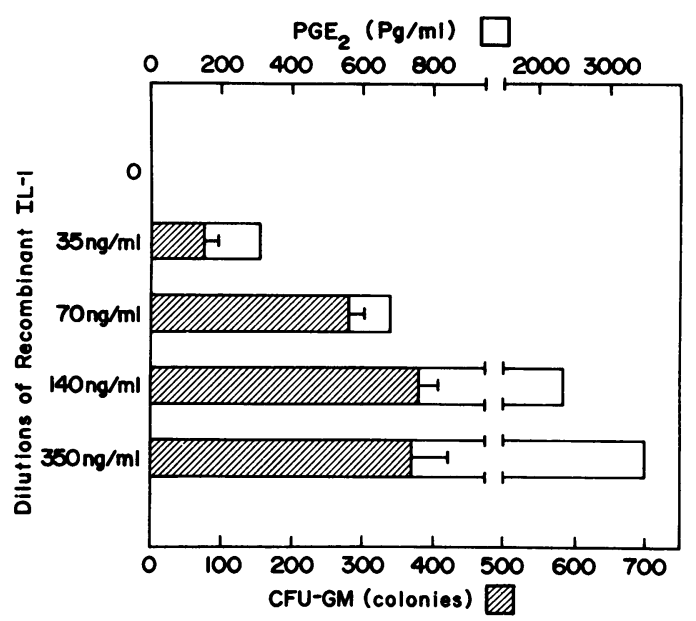

Figure 3. Influence of recombinant IL-1 (pI 7) on GM-CSA and $\mathrm{PGE}_{2}$ production by fibroblast monolayers. Decreasing concentrations (from 350 to $35 \mathrm{ng} / \mathrm{ml}$ ) recombinant IL-1 were added to confluent cultures of fibroblasts for $24 \mathrm{~h}$. The resultant fibroblast-conditioned medium was assayed in the CFU-GM colony assay and for $\mathrm{PGE}_{2}$ using a radioimmunoassay. Each hatched bar represents the mean CFU-GM (colonies) \pm 1 SEM of five to six observations. Each open bar represents the mean $\mathrm{PGE}_{2}$ value from duplicate observations taken from the dose-response curve for $\mathrm{PGE}_{2}$.

However, when only $10 \%$ of this monocyte-conditioned medium was placed on fibroblast monolayers, all GM-CSA activity was abolished in the presence of antibody. To show that the presence of the anti-IL-1 did not affect the colony assay, anti-IL-1 was added together with conditioned medium from the bladder carcinoma cell line 5637. Anti-IL-1 had no effect on colony formation. In addition, anti-IL-1 does not appear to have a direct effect on the production of GM-CSA by fibroblast monolayers.

Table III. Influence of Anti-IL-1 on the Ability

of Monocyte-conditioned Medium to Stimulate GM-CSA and $P G E_{2}$ Production by Fibroblast Cultures

\begin{tabular}{llr}
\hline Source of GM-CSA & $\begin{array}{l}\text { Number of CFU-GM } \\
\text { (colonies) }\end{array}$ & \multicolumn{1}{c}{ PGE $_{2}$} \\
\hline & & $p g / m l$ \\
$5637 \mathrm{CM}$ & $170 \pm 23^{*}$ & - \\
$5637 \mathrm{CM}+$ anti-IL-1 & $173 \pm 5$ & - \\
FCM $_{\text {control }}$ & 0 & $<20$ \\
FCM $_{\mathrm{IL}-1}$ & $198 \pm 17$ & 724 \\
FCM $_{\mathrm{IL}-1}+$ anti-IL-1 & 0 & $<20$ \\
FCM $_{50 \%}$ MCM & $176 \pm 1$ & 217 \\
FCM $_{50 \%}$ MCM + anti-IL-1 & 0 & $<20$ \\
FCM $_{50 \%}$ MCM-LPS & $200 \pm 16$ & 1498 \\
FCM $_{50 \%}$ MCM-LPS + anti-IL-1 & $22 \pm 9$ & 63 \\
FCM $_{10 \%}$ MCM-LPS & $169 \pm 7$ & 179 \\
FCM $_{10 \%}$ MCM-LPS + anti-Il-1 & 0 & $<20$ \\
\end{tabular}

Human bladder carcinoma 5637-conditioned medium (CM), IL-1, or 2-d monocyte-conditioned medium (MCM) were incubated overnight at $4^{\circ} \mathrm{C}$ with or without a $1: 100$ dilution of anti-IL-1, and placed on fibroblast monolayers for $24 \mathrm{~h}$. The resultant fibroblast supernatant (FCM) was harvested and assayed for GM-CSA and $\mathrm{PGE}_{2}$ production. * Results are expressed as means \pm 1 SEM. 
For these experiments (Table IV), monokine was added to fibroblast monolayers for $8 \mathrm{~h}$. At this time, the fibroblast-conditioned medium was removed and saved for assay. The fibroblast monolayer was washed with complete medium and then replaced with either complete medium or medium containing anti-IL-1 for an additional $16 \mathrm{~h}$ of culture. Assay of this $16-\mathrm{h}$ conditioned medium for GM-CSA showed that there were no differences in the ability of fibroblasts to continue to produce and release GMCSA in the presence or absence of anti-IL-1.

In the course of these studies a second hrIL-1 (ROO6T) became available with an amino acid sequence starting at position 112 instead of 71 . This site is closer to the reported N-terminus (amino acid 117) for human monocyte-derived IL-1 with a neutral pI (36). As shown in Table V, ROO6T hrlL-1 stimulated fibroblasts to produce GM-CSA at a 1.0-1.5 log lower concentration than that seen by ROO6B hrIL-1. Because the molecular weight of ROO6T hrIL-1 is 17,000, it can be calculated that the amount necessary to stimulate confluent fibroblasts to produce detectable GM-CSA is $\sim 10^{-10} \mathrm{M}$.

In order to determine whether the secretion of IL-1 by cultured monocytes and GM-CSA production by stimulated fibroblasts depended on de novo protein synthesis, experiments were carried out to evaluate the effects of cycloheximide on both IL1 and GM-CSA production. As outlined in Table VI, the addition of $10 \mu \mathrm{g}$ of cycloheximide reduced the secretion of IL-1 by monocytes to $15 \%$ of control and GM-CSA production by fibroblasts to $4 \%$ of control. Prior to assay for GM-CSA, all media were extensively dialyzed to eliminate the inhibitor. Thus, GMCSA is both produced and released by fibroblasts and IL-1 is also produced and released during the culture of monocytes.

Finally, colonies were fixed and stained and classified into three subtypes: pure neutrophilic granulocyte colonies showing only chloroacetate esterase-positive cells, mixed granulocytemacrophage colonies with a mixture of chloroacetate esterasepositive cells and butyrate esterase-positive cells, and pure macrophage colonies with only butyrate esterase-positive cells. Table VII shows that all three subtypes of colonies were observed at both 7 and $14 \mathrm{~d}$ of culture. Higher numbers of granulocyte colonies were seen at $7 \mathrm{~d}$ of culture while samples analyzed on day 14 exhibited an increase in the percentage of macrophage colonies. Thus IL-1 stimulates fibroblasts to produce a GM-CSA.

Table IV. Effect of Anti-IL-1 on GM-CSA Production by Fibroblast Monolayers after Stimulation by Monocyte-conditioned Medium for $8 \mathrm{~h}$

\begin{tabular}{ll}
\hline Source of GM-CSA & $\begin{array}{l}\text { Number of CFU-GM } \\
\text { (colonies + clusters) }\end{array}$ \\
\hline A. FCM & \\
B. FCM $8 \mathrm{~h}$ & $139 \pm 43^{*}$ \\
C. FCM & $185 \pm 33$ \\
\hline
\end{tabular}

2-d monocyte-conditioned medium (MCM) was added to fibroblast monolayers for $8 \mathrm{~h}$. The resultant fibroblast-conditioned medium $\left(\mathrm{FCM}_{\mathrm{MCM}}\right)$ was removed for GM-CSA assay $(A)$. After washing the fibroblast monolayer, either complete medium $(B)$ or medium containing a 1:100 dilution of anti-IL-1 $(C)$ was added to the fibroblasts for an additional $16 \mathrm{~h}$ of culture.

* Results are expressed as means \pm 1 SEM.
Table V. Influence of Two Different hrIL-1 preparations (R006B, a 24.5-kD Molecule Containing Amino Acids 71-269 and R006T, a 17.0-kD Molecule Containing Amino Acids 112-269) on GM-CSA Production by Fibroblast Monolayers.

\begin{tabular}{|c|c|}
\hline Source of GM-CSA & Number of CFU-GM colonies \\
\hline hrIL-1 R006B* $350 \mathrm{ng} / \mathrm{ml}$ & 0 \\
\hline hrIL-1 R006T $\ddagger 230 \mathrm{ng} / \mathrm{ml}$ & 0 \\
\hline $\mathrm{FCM}_{\text {control }}$ & 0 \\
\hline $\mathrm{FCM}_{\mathrm{hrIL}-1 \mathrm{R}} 006 \mathrm{~B} 350 \mathrm{ng} / \mathrm{ml}$ & $175 \pm 14 \S$ \\
\hline $\mathrm{FCM}_{\mathrm{hrlL}-1} \mathrm{R} 006 \mathrm{~B} 140 \mathrm{ng} / \mathrm{ml}$ & $185 \pm 9$ \\
\hline $\mathrm{FCM}_{\mathrm{hrIL}-1} \mathrm{R} 006 \mathrm{~B} 70 \mathrm{ng} / \mathrm{ml}$ & $157 \pm 16$ \\
\hline $\mathrm{FCM}_{\mathrm{hrlL}-1} \mathrm{R} 006 \mathrm{~B} 35 \mathrm{ng} / \mathrm{ml}$ & $50 \pm 14$ \\
\hline $\mathrm{FCM}_{\mathrm{hrlL}-1 \mathrm{R} 006 \mathrm{~B} 14 \mathrm{ng} / \mathrm{ml}}$ & 0 \\
\hline $\mathrm{FCM}_{\mathrm{hrIL}-1} \mathrm{R006 \textrm {T }} 230 \mathrm{ng} / \mathrm{ml}$ & $170 \pm 10$ \\
\hline $\mathrm{FCM}_{\mathrm{hrIL}-1} \mathrm{R} 006 \mathrm{~T} 23 \mathrm{ng} / \mathrm{ml}$ & $174 \pm 9$ \\
\hline $\mathrm{FCM}_{\mathrm{hrlL}-1} \mathrm{R006 \textrm {T }} 2.3 \mathrm{ng} / \mathrm{ml}$ & $103 \pm 13$ \\
\hline $\mathrm{FCM}_{\mathrm{hrlL}-1} \mathrm{R} 006 \mathrm{~T} 0.23 \mathrm{ng} / \mathrm{ml}$ & $0.3 \pm 0.6$ \\
\hline
\end{tabular}

FCM, fibroblast-conditioned medium.

* hrIL-1 R006B, hrIL-1 containing amino acids 71-269.

$\ddagger$ hrlL-1 R006T, human recombinant hrIL-1 containing amino acids 112-269.

$\S$ Results are expressed as means \pm 1 SEM.

\section{Discussion}

The results presented in this study have confirmed that cultured monocytes produce and release a monokine that stimulates fibroblasts to produce and release GM-CSA and $\operatorname{PGE}_{2}(18,20)$. This monokine has been identified as IL-1 since both purified and recombinant IL-1 can mimic the activity found in monocyte conditioned medium. In addition, a polyclonal rabbit antibody specific for human monocyte IL-1 completely abolished the ability of monocyte-derived monokine to induce fibroblast cultures to produce GM-CSA and $\mathrm{PGE}_{2}$.

Addition of monocyte-conditioned medium or IL-1 to fibroblast monolayers results in a marked increase in GM-CSA produced with detectable levels being found after $4 \mathrm{~h}$ of incubation. Maximum levels occurred between 8 and $48 \mathrm{~h}$ of cultures

Table VI. Effect of the Protein Synthesis Inhibitor Cycloheximide on Monocyte IL-1 and Fibroblast GM-CSA Production*

\begin{tabular}{lcc}
\hline Group & GM-CSA colonies & \% of control \\
\hline A. FCM $_{\mathrm{MCM}}$ & $184 \pm 5^{*}$ & 100 \\
B. $\mathrm{FCM}_{(\mathrm{MCM}+\text { cycloheximide) }}$ & $27 \pm 16$ & 15 \\
C. $\mathrm{FCM}_{\mathrm{MCM}}+$ cycloheximide & $7 \pm 3$ & 4 \\
\hline
\end{tabular}

For monocyte IL-1 production, medium without $(A)$ or with $(B)$ cycloheximide $(10 \mu \mathrm{g} / \mathrm{ml})$ was added to monocyte cultures at the start of incubation. After $2 \mathrm{~d}$ of culture, both groups $(A$ and $B)$ were dialyzed to remove inhibitor prior to placing over fibroblast monolayers at $50 \%$ for $24 \mathrm{~h}$. The resultant fibroblast-conditioned medium (FCM) was assayed at $10 \%$ for GM-CSA activity. For fibroblast GM-CSA production $(C)$, cycloheximide $(10 \mu \mathrm{g} / \mathrm{ml})$ was added to fibroblast cultures at the time of addition of 50\% monocyte-conditioned medium (MCM). After $24 \mathrm{~h}$, group $(C)$ was dialyzed to removed inhibitor prior to assaying at $10 \%$ for GM-CSA activity.

* Results are expressed as mean \pm 1 SEM. 
Table VII. Cytochemical Analysis of Individual CFU-GM Colonies

\begin{tabular}{|c|c|c|c|}
\hline \multirow[b]{2}{*}{ Source of GM-CSA } & \multicolumn{3}{|l|}{ Colonies } \\
\hline & G & Mix & $\mathbf{M}$ \\
\hline & $\%$ & $\%$ & \% \\
\hline \multicolumn{4}{|l|}{ Day 7} \\
\hline $5637 \mathrm{CM}^{*}$ & $68 \pm 5^{\prime \prime}$ & $28 \pm 3$ & $4 \pm 2$ \\
\hline $\mathrm{FCM}_{\mathrm{IL-1}} \ddagger$ & $45 \pm 9$ & $42 \pm 7$ & $13 \pm 4$ \\
\hline $\mathrm{FCM}_{\mathbf{M C M}} \S$ & $49 \pm 6$ & $36 \pm 3$ & $15 \pm 5$ \\
\hline \multicolumn{4}{|l|}{ Day 14} \\
\hline $5637 \mathrm{CM}$ & $45 \pm 7$ & $46 \pm 2$ & $9 \pm 4$ \\
\hline $\mathrm{FCM}_{\mathrm{IL}-1}$ & $15 \pm 7$ & $51 \pm 7$ & $34 \pm 8$ \\
\hline $\mathrm{FCM}_{\mathrm{MCM}}$ & $19 \pm 5$ & $47 \pm 13$ & $36 \pm 11$ \\
\hline
\end{tabular}

G, neutrophilic granulocyte; MIX, neutrophilic granulocytic and macrophage; $\mathbf{M}$, macrophage.

* Human bladder carcinoma 5637 conditioned medium.

$¥$ Resulting fibroblast-conditioned medium after stimulation with IL-1 for $24 \mathrm{~h}$.

$\S$ Resulting fibroblast-conditioned medium after stimulation by $50 \%$ monocyte conditioned medium for $24 \mathrm{~h}$.

" Results are expressed as means \pm 1 SEM.

(Fig. 1). While endotoxin (LPS) stimulated increased levels of IL-1 production by monocytes, fibroblast cultures did not produce GM-CSA in the presence or absence of LPS. Thus, in this system, LPS appears to exert its effect on colony formation through an increase in IL-1 production by monocytes.

In this report we have shown that fibroblast $\mathrm{PGE}_{2}$ production was also stimulated by monocyte-conditioned medium or IL-1. This has been previously reported by others (21-23). Because previous reports have suggested that $\mathrm{PGE}_{2}$ may counteract the stimulatory effects of GM-CSA by suppressing CFU-GM proliferation (37) or may inhibit production of GM-CSA by stimulated monocytes (38), we cultured both monocytes and fibroblasts in the presence and absence of indomethacin. While $\mathrm{PGE}_{2}$ production was completely inhibited by the addition of indomethacin $\left(10^{-6} \mathrm{M}\right)$, we were unable to find increased concentrations of detectable GM-CSA in the supernatant of endotoxinstimulated monocytes or in the supernatants of fibroblast cultures stimulated with monocyte-conditioned medium or IL-1. These results indicate that the amount of $\mathrm{PGE}_{2}$ synthesized by stimulated fibroblasts $\left(10^{-9}\right.$ to $\left.10^{-8} \mathrm{M}\right)$ in this system does not produce an inhibitory effect on fibroblast GM-CSA production. This is probably due to the fact that $\mathrm{PGE}_{2}$ inhibits mainly macrophage colonies except at concentrations $>10^{-6} \mathrm{M}$ (39).

Recently, Bagby et al. (16-18) have demonstrated that GMCSA production by $\mathrm{T}$ lymphocytes, endothelial cells, and fibroblasts is stimulated by a soluble monocyte product which they have termed monocyte-derived recruiting activity (MRA). They have also proposed that MRA production may represent the means by which monocytes regulate steady-state granulopoiesis. In this study, we have been able to corroborate that monocytes produce a factor which induces fibroblasts to produce GM-CSA (Table II) and have identified this factor as interleukin 1 (Table IV). Whether IL-1 is a universal monokine and will also stimulate other cells (i.e., $T$ lymphocytes or endothelial cells to produce GM-CSA) is not known at present. In addition, it is unknown whether IL-1 may also stimulate these same types of accessary cells to produce other growth factors such as burst-promoting activity (BPA), megakaryocyte-CSA, or mixed granulocytemacrophage CSA. Studies on the production of these other growth factors as well as the interaction of endothelial cells and IL-1 are currently in progress.

Human monocyte-derived IL-1 represents a family of polypeptides with multiple biologic activities. Recently, considerable interest has been generated in the study of IL-1 as a mediator of host responses to infection, injury and various immunological reactions (20). How many of the biologic activities ascribed to IL-1 are due to a single substance has only begun to be studied with the cloning of cDNAs coding for human monocyte-derived IL-1 (33). At present, there seems to be a minimum of at least two distinct forms of IL-1 $(33,40)$, which are based on two major isoelectric points, pI 7 and pI 5. Because of the role of IL-1 in neutrophil release from bone marrow (41) and its role as a chemoattractant for neutrophils and monocytes in vitro $(42,43)$, it is perhaps not surprising that it may also play a role in granulocyte and monocyte production. The two purified hrIL1's with a pI 7 (33) used in this study were both shown to be active in stimulating fibroblast monolayers to produce and release both GM-CSA and PGE 2 . ROO6T hrIL-1, containing an amino acid sequence starting at position 112 which is close to the $\mathrm{N}$ terminus of IL-1, stimulated fibroblasts to produce detectable GM-CSA at a dose of about $10^{-10} \mathrm{M}$. Thus, elimination of 111 of the 116 amino acids that are part of the precursor peptide did not prevent induction of GM-CSA production by cultured fibroblasts. Whether other forms (i.e., pI 5) will also possess this property remains unknown.

\section{Acknowledgments}

This study was supported by grants AI-15614 to Dr. Dinarello and CA29266 to Dr. Weiner from the National Institutes of Health and grant CH 260 to Dr. Oblon from the American Cancer Society.

\section{References}

1. Chervenick, P. A., and A. F. LoBuglio. 1972. Human blood monocytes: stimulators of granulocyte and mononuclear colony formation in vitro. Science (Wash. DC). 178:164-166.

2. Golde, D. W., and M. J. Cline. 1972. Identification of colonystimulating cells in human peripheral blood. J. Clin. Invest. 51:29812983.

3. Cline, M. J., and D. W. Golde. 1974. Production of colony-stimulating activity by human lymphocytes. Nature (Lond.). 248:703-704.

4. Ruscetti, F. W., and P. A. Chervenick. 1975. Release of colonystimulating activity from thymus-derived lymphocytes. J. Clin. Invest. 55:520-527.

5. Knudtzon, S., and B. T. Mortenson. 1975. Growth stimulation of human bone marrow cells in agar culture by vascular cells. Blood. 46: 937-943.

6. Quesenberry, P. J., and M. A. Gimbrone. 1980. Vascular endothelium as a regulator of granulopoiesis: production of colony-stimulating activity by cultured human endothelial cells. Blood. 56:1060-1067.

7. Guez, M., and L. Sachs. 1973. Purification of the protein that induces cell differentiation to macrophages and granulocytes. FEBS (Fed. Eur. Biochem. Soc.) Lett. 37:149-154.

8. Quesenberry, P. A., A. Morley, F. Stohlman, Jr., K. Rickard, D. Howard, and M. Smith. 1972. Effect of endotoxin on granulopoiesis and colony-stimulating factor. $N$. Engl. J. Med. 286:227-232.

9. Cline, M. J., B. Rothman, and D. W. Golde. 1974. Effect of endotoxin on the production of colony-stimulating factor by human monocytes and macrophages. J. Cell. Physiol. 84:193-196. 
10. Sullivan, R., P. J. Gans, and L. A. McCarroll. 1983. The synthesis and secretion of granulocyte-monocyte colony-stimulating activity (CSA) by isolated human monocytes: kinetics of the response to bacterial endotoxin. J. Immunol. 130:800-807.

11. Parker, J. W., and D. Metcalf. 1974. Production of colony-stimulating factor in mitogen-stimulated lymphocyte cultures. J. Immunol. 112:502-510.

12. Shah, R. G., L. H. Caporale, and M. A. S. Moore. 1977. Characterization of colony-stimulating activity produced by human monocytes and phytohemagglutinin-stimulated lymphocytes. Blood. 50:811-821.

13. Verma, D. S., G. Spitzer, A. R. Zander, R. Fischer, K. B. McCredie, and K. A. Dickie. 1979. T-lymphocyte and monocyte-macrophage interaction in colony-stimulating activity elaboration in man. Blood. 54:1376-1383.

14. Apte, R. N., E. Heller, C. F. Hertogs, and D. H. Pluznik. 1979. Macrophages as regulators of granulopoiesis. Adv. Exp. Med. Biol. 121: 433-449.

15. Hesketh, P. J., R. Sullivan, C. R. Valeri, and L. A. McCarroll. 1984. The production of granulocyte-monocyte colony-stimulating activity by isolated human T lymphocyte subpopulations. Blood. 63:11411146.

16. Bagby, G. C., V. D. Rigas, R. M. Bennett, A. A. Vandenbark, and H. S. Garewal. 1981. Interaction of lactoferrin, monocytes and T lymphocyte subsets in the regulation of steady-state granulopoiesis in vitro. J. Clin. Invest. 68:56-63.

17. Bagby, G. C., E. McCall, K. A. Bergstrom, and D. Burger. 1983. A monokine regulates colony-stimulating activity production by vascular endothelial cells. Blood. 62:663-668.

18. Bagby, G. C., E. McCall, and D. L. Layman. 1983. Regulation of colony-stimulating activity production: interactions of fibroblasts, mononuclear phagocytes and lactoferrin. J. Clin. Invest. 71:340-344.

19. McCall, E., and G. C. Bagby. 1985. Monocyte-derived recruiting activity: kinetics of production and effects of endotoxin. Blood. 65:689695.

20. Dinarello, C. A. 1984. Interleukin-1. Rev. Infect. Dis. 6:51-95.

21. Korn, J. H., P. V. Halushka, and E. C. LeRoy. 1980. Mononuclear cell modulation of connective tissue function. Suppression of fibroblast growth by endogenous prostaglandin production. J. Clin. Invest. 65:543554.

22. Dayer, J.-M., D. R. Robinson, and S. M. Krane. 1972. Prostaglandin production by rheumatic synovial cells: stimulation by a factor from human mononuclear cells. J. Exp. Med. 145:1399-1404.

23. Clark, J. G., K. M. Kostal, and B. A. Marino. 1983. Bleomycininduced pulmonary fibrosis in hamsters. J. Clin. Invest. 72:2082-2091.

24. Dayer, J. M., M. L. Stephens, E. Schmidt, W. Karge, and S. M. Krane. 1981. Purification of a factor from human-blood monocyte-macrophages which stimulates the production of collagenase and prostaglandin $\mathrm{E}_{2}$ by cells cultured from rheumatoid synovial tissues. FEBS (Fed. Eur. Biochem. Soc.) Lett. 12:253-256.

25. Bernhein, H. A., and C. A. Dinarello. 1985. Effects of purified human interleukin-1 on the release of prostaglandin $\mathrm{E} 2$ from fibroblasts. Br. J. Rheumatol. 24:122-127.

26. Weiner, R. S., C. M. Richman, and R. A. Yankee. 1977. Semicontinuous flow centrifugation for the pheresis of immunocompetent cells and stem cells. Blood. 49:391-397.

27. Weiner, R. S., and V. O. Shah. 1980. Purification of human monocytes: isolation and collection of large numbers of peripheral blood monocytes. J. Immunol. Methods. 36:89-97.

28. Mason, R. R., and R. S. Weiner. 1984. Application of the Bechman JE6-B elutriator system in the isolation of human monocyte subpopulations. Scand. J. Haematol. 34:5-8.

29. Yan, T. L., C. Y. Li, and W. H. Crosby. 1971. Cytochemical identification of monocytes and granulocytes. Am. J. Clin. Pathol. 55: 283-290.

30. Kurland, J. I., and R. S. Bockman. 1979. Prostaglandin E production by human monocytes and mouse macrophages. J. Exp. Med. 147:952-957.

31. Dinarello, C. A., H. A. Bernheim, J. G. Cannon, G. LoPreste, S. J. C. Warner, A. C. Webb, and P. E. Auron. 1985. Purified, ${ }^{35}$ S-met, ${ }^{3} \mathrm{H}$-leu-labeled human monocyte interleukin-1 with endogenous pyrogen activity. Br. J. Rheumatol. 24:56-61.

32. Dinarello, C. A., L. Renfer, and S. M. Wolff. 1977. Human leukocytic pyrogen: purification and development of a radio-immuno-assay. Proc. Natl. Acad. Sci. USA. 74:4624-4627.

33. Auron, P. E., A. C. Webb, L. J. Rosenwasser, S. F. Mucci, A. Rich, S. M. Wolff, and C. A. Dinarello. 1984. Nucleotide sequence of human monocyte interleukin-1 precursor cDNA. Proc. Natl. Acad. Sci. USA. 81:7907-7911.

34. Levin, J. 1982. The limulus test and bacterial endotoxins: some perspectives. In Endotoxins and their Detection with the Limulus Amebocyte Lysate Test. S. W. Watson, J. Levin, and T. J. Novitsky, editors. A. R. Liss Inc., New York. 7-24.

35. Kubota, K., H. Mizoquchi, Y. Miura, T. Suda, and F. Takaku. 1980. A new technique for the cytochemical examination of human hemopoietic cells grown in agar gel. Exp. Hematol. 8:339-344.

36. Van Damme, J., M. DeLey, G. Opdenakker, A. Billian, and P. DeSomer. 1985. Homogeneous interferon-inducing $22 \mathrm{~K}$ factor is related to endogenous pyrogen and interleukin-1. Nature (Lond.). 314:266-268.

37. Kurland, J. I., H. E. Broxmeyer, R. S. Bockman, and M. A. S. Moore. 1978. Role for the monocyte macrophage colony stimulating factor and prostaglandin $\mathrm{E}$ in the positive and negative feedback control of myeloid stem cell proliferation. Blood. 52:388-401.

38. Moore, R. N., R. Urbaschek, L. M. Wahl, and S. E. Mergenhagen. 1979. Prostaglandin regulation of colony-stimulating factor production by lipopolysaccharide-stimulated murine leukocytes. Infect. Immun. 26 : 408-414.

39. Pelus, L. M., H. E. Broxmeyer, and M. A. S. Moore. 1981. Regulation of human myelopoiesis by prostaglandin $\mathrm{E}$ and lactoferrin. Cell Tissue Kinet. 14:515-526.

40. Lomedico, P. T., U. Gubler, C. P. Hellmann, M. Dukovich, J. G. Giri, Y.-C. E. Pan, K. Collier, R. Semionow, A. O. Chua, and S. B. Mizel. 1984. Cloning and expression of murine interleukin-1 cDNA in Escherichia coli. Nature (Lond.). 312:458-462.

41. Kampschmidt, R. F. 1984. Infection, inflammation, and interleukin-1. Lymphokine Res. 2:97-100.

42. Lugar, T. A., J. H. Charon, M. Colot, M. Mickscke, and J. J. Oppenheim. 1983. Chemotactic properties of partially purified human epidermal cell-derived thymocyte activating factor (ETAF), for polymorphonuclear and mononuclear cells. J. Immunol. 131:816-820.

43. Sauder, D. N., N. L. Mounessa, E. I. Katz, C. A. Dinarello, and J. I. Gallin. 1984. Chemotactic cytokine: the role of leukocytic pyrogen and epidermal cell thymocyte-activating factor in neutrophil chemotaxis. J. Immunol. 132:828-832. 